\title{
GREEN SYNTHESIS OF MAGNETIC IRON NANOPARTICLES USING MEDICINAL PLANT TRIDAX PROCUMBENS LEAF EXTRACTS AND ITS APPLICATION AS AN ANTIMICROBIAL AGENT AGAINST E. COLI
}

\author{
YOJANA Y. PATIL*, VAISHNVI B. SUTAR, ARPITA P. TIWARI ${ }^{\#}$
}

*School of Nano-Science and Technology, Shivaji University, Kolhapur, "Stem Cell and Regenerative Medicine, Centre for Interdisciplinary Research, DYPES, Kolhapur

Email: yojana.yp@gmail.com

Received: 19 Mar 2020, Revised and Accepted: 22 Jul 2020

\begin{abstract}
Objective: The present study was aimed at the biological synthesis of magnetic iron nanoparticles by using the plant extract of Tridax procumbens and also to study their antimicrobial property against gram-negative bacteria (Escherichia coli).

Methods: The synthesis of magnetic iron nanoparticles was carried out by the co-precipitation method using biological methods like plant extract as reducing agent and capping agents are biocompatible and non-hazardous. These nanoparticles were characterized by UV-Visible spectroscopy, XRD (X-Ray Diffraction), and SEM (Scanning Electron Microscope). As well as antibacterial activity of the nanoparticles was carried out by agar well diffusion method and Most Probable Number (MPN) method against gram-negative E. coli (Escherichia coli) bacteria.

Results: The average crystallite size of Magnetic Nanoparticles (MNPs) was found to be 72 nm by X-ray diffraction. The optical absorption band at wavelengths of $240 \mathrm{~nm}$ and $402 \mathrm{~nm}$ was obtained from the UV Visible spectrum. Spherical shape morphology was observed in SEM studies. The antibacterial assay clearly expressed that $E$. coli showed a maximum zone of inhibition $(15 \pm 0.15 \mathrm{~mm})$ at $2 \mathrm{mg} / \mathrm{ml} \mathrm{and} 1 \mathrm{mg} / \mathrm{ml}$ concentration was found for Magnetic Nanoparticles. In the Most Probable Number (MPN) test it is seen that the bacterial count is reduced after adding synthesized NPs into the water sample.
\end{abstract}

Conclusion: The results of the present study conclude that the Magnetic Nanoparticles synthesized using Tridax procumbens leaf extracts is found to be stable and show good antibacterial activity against gram-negative (Escherichia coli) bacteria.

Keywords: Green synthesis, Magnetic Nanoparticles, XRD, UV-VISIBLE spectroscopy, SEM, Antimicrobial

(C) 2020 The Authors. Published by Innovare Academic Sciences Pvt Ltd. This is an open access article under the CC BY license (http://creativecommons.org/licenses/by/4.0/) DOI: http://dx.doi.org/10.22159/ijap.2020.v12s4.40102. Journal homepage: https://innovareacademics.in/journals/index.php/ijap

\section{INTRODUCTION}

Nanomaterials and nanoparticles are considered to be the advanced and significant approaches for the bioremediation and purification of wastewater. There are nanotechnology-based processes and products in wastewater treatment and water purification like nano adsorbents (natural products, activated carbon, zeolites, aluminosilicate, polysaccharides, carbon nanomaterials etc.), magnetic nanoparticles, nanofiltration, nano zero-valent iron, nanocatalyst, nanofibers, nanobiocides [1]. In these processes and products magnetic nanoparticles are an interesting and emerging option for the treatment of contaminated water. Due to their small size, the particles are very reactive and can be used in many biological treatments. Magnetism is a unique physical property that independently aid in water purification by influencing the physical properties of many contaminants in water. In addition, if it is combined with other processes enables an improvised, efficient purification technology [2].

Magnetic nanoparticles (MNPs) are those nanoparticles (NPs) that show some reaction to an applied magnetic field. Nanotechnology allocates physicists, chemists, material scientists and engineers to make systems with nano sizes where the classic laws of physics are varied at that small scale. With decreasing size of particles, the ratio of the surface area to the volume of the particle increases. For nanoparticles, this ratio becomes significantly huge, causing a large section of the atoms to reside on the surface compared to those in the core of the particle. As per the studied example, for a particle of 1 $\mu \mathrm{m}$ in diameter, nearly $0.15 \%$ of its atoms are on the surface, while for a particle of $6 \mathrm{~nm}$ in diameter, nearly $20 \%$ of its atoms are on the surface [3].

Many recent studies have indicated the potential of magnetic iron nanoparticles (NPs) for environmental remediation. Nanoscale materials such as nano adsorbents, nanocatalysts, nanofiltration, and nanobiocides such as metal and metal oxide nanoparticles are at present being working for the remediation technique of water and wastewater pollutants. Among these metallic nanoparticles, iron nanoparticles (FeNPs) have capable advantages that can tackle environmental pollution. The interest in nanoscale zero-valentiron (nZVI) in environmental remediation is increasing due to the reactivity of nanoscale iron having ablarge surface area to volume ratio [4]. The synthesis of iron nanomaterials, such as metallic iron and oxide of iron by a more convenient eco-friendly route, is a great step forward in the development of nanomaterials. The importance of the biogenic approaches has the role of biocompatible green materials in technological as well as in economically viable process and practices. It also summarizes the search for an environmentally sustainable synthesis process of iron nanomaterials for their environmental sustainability in an applied manner [5]. Magnetic nanoparticles based pathogen detection has gained ground in recent years because of the high physical and chemical stability and the potentially low-cost of production of magnetic particle nanobeads. In the medical sector Magnetic nanoparticles-DNA interactions can open up new possibilities in various biomedical applications [6, 7].

The synthesis of magnetic iron nanoparticles is done by biological method by using plant extract. This research aims to synthesize MNP by green route method and to access the capability of these materials to treat contaminated groundwater. In this research work it is intended to synthesize the magnetic iron nanoparticles by using plant extract of Tridax procumbens. The plant Tridax procumbens is popularly known as coat button. It is a common weed found in open space. Traditionally it is used for the treatment of bronchial catarrh, dysentery, malaria, stomach ache, high blood pressure, wound healing, hair fall control etc [8]. So it is a medicinal plant. Tridax procumbens has been used for the synthesis of iron nanoparticles [9]. After the synthesis of magnetic iron nanoparticles, we have checked its antimicrobial activity by using disk diffusion method. In this research, we have used the synthesized nanoparticles for the treatment of water samples by checking the MPN parameters of 
water uses for bacterial count. Considering growing cities and the future demand of water, old wells once used for water supply in the city, may be rejuvenated. Ground water has been abused mostly during the past decade due to the use of wells as a waste dumping site which shows having high bacterial contamination with MPN test, which make it unsuitable to drink [10]. That's why Magnetic nanoparticles also show its application to reduce coliform bacterial contaminations working as antibacterial agent.

\section{MATERIALS AND METHODS}

\section{Preparation of plant extract}

Plant of Triadx procumbens was collected from the garden of Shivaji University, Kolhapur. Plant material was washed thoroughly with tap water and shade dried for $7 \mathrm{~d}$. coarse powder of leaves was obtained by crushing the leaves in an electric blender. Then powder was added in water and boiled in hot water bath for $20 \mathrm{~min}$ at $98{ }^{\circ} \mathrm{C}$. Then the extract was collected by filtration of the solution. The filtrate obtained was then centrifuged at $10000 \mathrm{rpm}$ for $10 \mathrm{~min}$. The supernatant was used as a plant extract for the synthesis of iron nanoparticles [9].

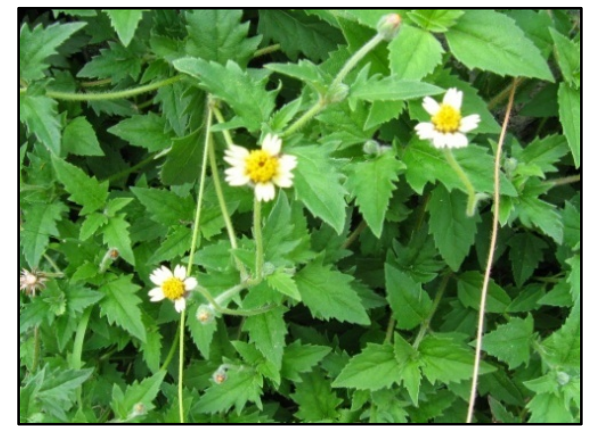

Fig. 1: Plant of Triadx procumbens

\section{Synthesis of iron nanoparticles}

Both the precursor and the reducing agent i.e. $0.001 \mathrm{M} \mathrm{FeCl} 3$ solution and plant extract, were mixed in a clean sterilized flask in $1: 1(\mathrm{~V} / \mathrm{V})$ proportion. For the reduction of iron ions, prepared plant extract was added in freshly prepared ferric chloride solution with constant stirring using magnetic stirrer. After 20 min the colour turned dark green to black indicating the synthesis of iron nanoparticles. Centrifugation of the solution was done for isolating the iron nanoparticles. The supernatant was then discarded and the pallet remained was washed with distilled water. Then the synthesized iron nanoparticles were kept in oven at $600{ }^{\circ} \mathrm{C}$ for $24 \mathrm{~h}$ for the drying process. Iron nanoparticles then collected in tube and stored for characterization.

\section{Characterization techniques}

Nanoscience and technology is an emerging and key technology in current century. Properties of materials change drastically with reduction of size to nanoscale that is the fundamental of nanotechnology but measuring the dimension at the nanoscale is a difficult task. Although research is going on the synthesis of nanostructured and nanophasic materials, characterizing these materials is also an emerging and challenging field for scientists and technologists. Thus, nanotechnology has been motivated in the research activity on the discovery of characterization techniques to allow better control on particle size, size distribution, morphology, the surface composition of nanomaterials. The important techniques used to characterize these materials are XRD, UV, SEM, etc.

\section{Well and disc diffusion method}

In the well diffusion method, weighed amount of Nutrient Agar is dissolved in $100 \mathrm{ml}$ of distilled water. The medium will be heated to dissolve agar and to form a clear liquid. Sterilization of agar will be done in an autoclave at $121^{\circ} \mathrm{C}, 15 \mathrm{lb}$ pressure for $15 \mathrm{~min}$. The flask will allow cooling up to $50^{\circ} \mathrm{C}$ and then the medium is quickly poured into sterile plates under aseptic conditions. The medium is allowed to cool so as to produce solid agar plates. The inoculation of plates is to be done by specific microorganisms by spread plate technique and is allowed to dry; wells were made in the solidified agar plate by using a sterile borer. Test solution (aqueous iron nanoparticles) of specified concentration was then added on the created well by using sterile pipette and the plates were then kept in the refrigerator for 1 hour for diffusion followed by incubation at $37^{\circ} \mathrm{C}$ for $24 \mathrm{~h}$ [11]. In disc diffusion, the making of media is the same but instead of bores here we put small sterile disc later embedded in the desired solution to check antimicrobial activity.

MPN test to check the applicability of magnetic nanoparticles for water treatment:

Single and double strained MacConkey's broths were prepared for three sets. 5 tubes were prepared of doubled strained MacConkey's broth and 10 tubes were prepared of single strained MacConkey's broth for each set. Three samples were prepared one was simple well water (Sample A), second was nanoparticles treated water sample for $10 \mathrm{~min}$ time (Sample B), and third was nanoparticles added tap water for $24 \mathrm{~h}$ (Sample C). Then $10 \mathrm{ml}$ of water sample was inoculated into each of the double strained broth tubes. Then 1 $\mathrm{ml}$ of water sample was added into 5 tubes of single strained MacConkey's broth and $0.1 \mathrm{ml}$ of water sample was added into another 5 tubes of single strained MacConkey's broth. This was done for all three water samples. Then the all tubes were incubated at 37 ${ }^{\circ} \mathrm{C}$ for $24 \mathrm{~h}$. and then checked it for acid and gas formation after incubation. The numbers of presumptive positive tubes were recorded. Then for the results in the presumptive test we referred to the standard Macrades table [12].

\section{RESULTS AND DISCUSSION}

\section{Visual observation}

The colour of the product was observed before and after the annealing process. As shown in the following (fig. 2) the colour of the product was grey-black before the annealing and it turned brown (fig. 3) after the annealing. These results are similar when high temperature is given by [13] as per these paper $\mathrm{Fe}_{2} \mathrm{O} 3$ formed after high temperature and therefore there is colour change.

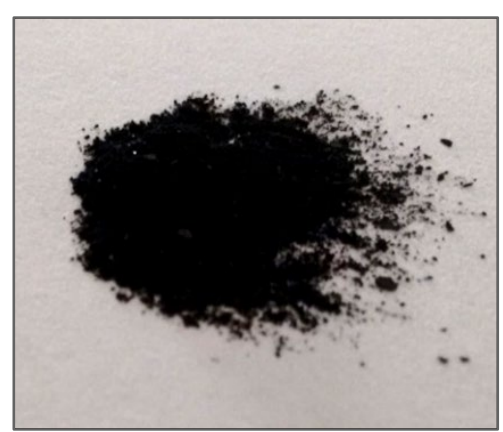

Fig. 2: Powder before annealing

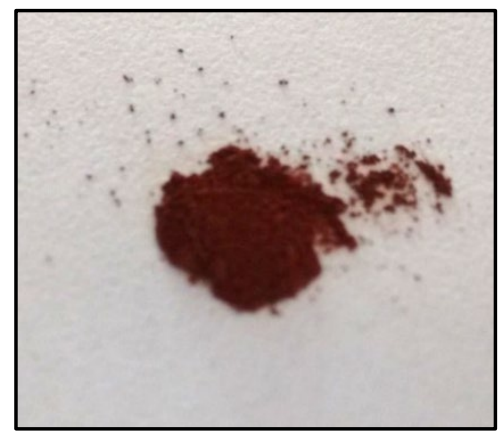

Fig. 3: Powder after annealing 


\section{Magnetic properties of nanoparticles}

Before the annealing nanoparticles were nonmagnetic; that is they didn't attract towards the magnet (fig. 4) but after the annealing, they attracted towards the magnet; that is, they became magnetic (fig. 5).

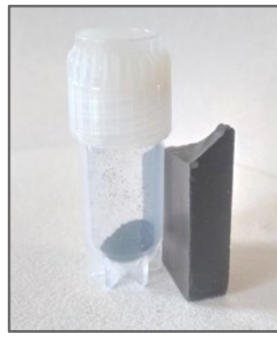

Fig. 4: Magnetization of powder before annealing

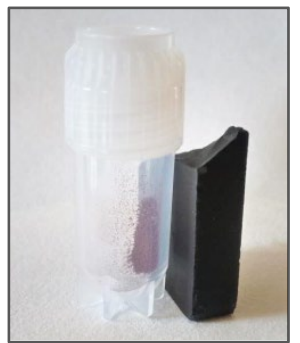

Fig. 5: Magnetization of powder before annealing

\section{Characterization}

\section{UV-VIS spectroscopy}

Ultraviolet-visible spectroscopy (UV-Vis) refers to absorption spectroscopy in the UV-Visible spectral region. This means it uses light in the visible and adjacent (near-UV and near-infrared) ranges. The absorption in the visible range directly affects the perceived colour of the chemicals mixed up. In this region of the electromagnetic spectrum, molecules undergo electronic transitions [14]. The UV Visible spectrum of Fe304-NPs is shown in fig. 6, particles have absorption peaks at wavelengths of $240 \mathrm{~nm}$ and 402 $\mathrm{nm}$ indicate the formation of iron nanoparticles as per results of some research paper $[5,14]$.

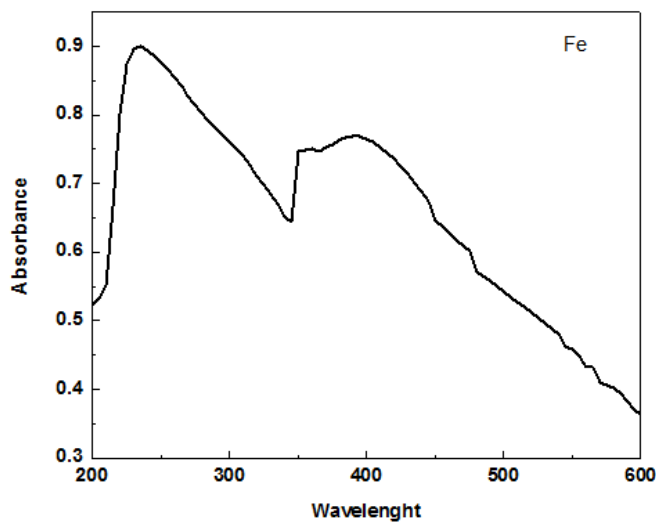

Fig. 6: UV-VIS spectra of synthesized nanoparticles

\section{X-ray diffraction}

In order to obtain the structural information of the product, the crystallographic structure of synthesized magnetic nanoparticles was analyzed by X-Ray diffraction (XRD). The crystallographic analysis of the sample in diffraction patterns was recorded from 100 to 700 with an analytical system diffractometer (Model no.:DY-

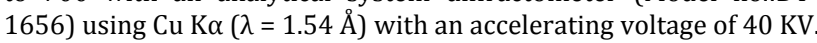
Data were collected with a counting rate of $10 / \mathrm{min}$. The K $\alpha$ doublets were well resolved.

The XRD graph of synthesized Iron oxide NP's shows the little peak at 311 plane, which match with standard Iron oxide NP's in both before and after annealing graph. The miller indices found at peaks $17.24,32.5$ and 39.06 are (111),(311) and (400) respectively for before annealing (fig. 7) while after annealing it shows peaks at $17.19,29.01,31.31$ and 34.91 are (111), (310), (311) and (320) respectively (fig. 8), phases of peaks changes can be seen in graph after annealing, similar results found in [15].

The crystallite size of synthesized nanoparticles after annealing by using Sherrer Formula $D=\frac{0.9 \times \lambda}{\beta \cos \theta}$ is $143 \mathrm{~nm}$ before annealing and 72 nm after annealing.

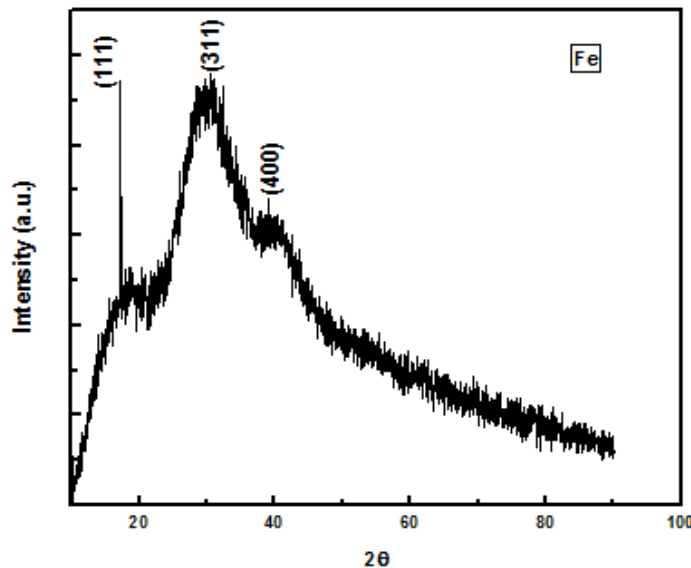

Fig. 7: XRD of Fe nanoparticles before annealing

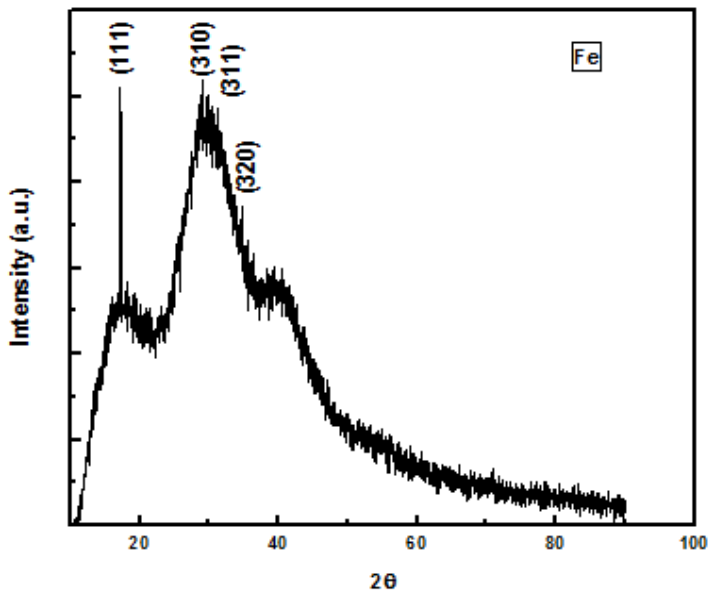

Fig. 8: XRD of Fe nanoparticles after annealing

Table 1: XRD data analysis and assignment of planes before annealing

\begin{tabular}{|c|c|c|c|c|c|c|c|c|c|}
\hline Peak No. & $2 \theta$ & $\Theta$ & $\operatorname{Sin} \theta$ & $\operatorname{Sin} 2 \theta$ & Ratio & Ratio x 2 & Ratio x 3 & h2+k2+l2 & (hkl) \\
\hline 1 & 17.24 & 8.62 & 0.1498 & 0.0022 & 1 & 2 & 3 & $1^{2}+1^{2}+1^{2}$ & (111) \\
\hline 2 & 32.27 & 16.13 & 0.277 & 0.076 & 3.45 & 6.9 & 10.35 & $3^{2}+1^{2}+1^{2}$ & (311) \\
\hline 3 & 39.06 & 19.53 & 0.334 & 0.111 & 5.24 & 10.48 & 15.72 & $4^{2}+0^{2}+0^{2}$ & $(400)$ \\
\hline
\end{tabular}


Table 2: XRD data analysis and assignment of planes after annealing

\begin{tabular}{|c|c|c|c|c|c|c|c|c|c|}
\hline Peak No. & $2 \theta$ & $\Theta$ & $\operatorname{Sin} \theta$ & $\operatorname{Sin}^{2} \theta$ & Ratio & Ratio x 2 & Ratio x 3 & $h^{2}+k^{2}+l^{2}$ & (hkl) \\
\hline 1 & 17.19 & 8.5 & 0.14 & 0.019 & 1 & 2 & 3 & $1^{2}+1^{2}+1^{2}$ & (111) \\
\hline 2 & 29.01 & 14.50 & 0.25 & 0.062 & 3.24 & 6.5 & 9.6 & $3^{2}+1^{2}+0^{2}$ & (310) \\
\hline 3 & 31.31 & 15.65 & 0.26 & 0.067 & 3.52 & 7 & 10.5 & $3^{2}+1^{2}+1^{2}$ & (311) \\
\hline 4 & 34.91 & 17.45 & 0.29 & 0.08 & 4.21 & 8.42 & 12.63 & $3^{2}+2^{2}+0^{2}$ & (320) \\
\hline
\end{tabular}

\section{SEM}

For the confirmation of morphology, SEM was taken. Fig. below show the images of synthesized nanoparticles at different magnification levels. The SEM images are shown in fig. 9 (a, b, c) at 5 $\mu \mathrm{m}, 2 \mu \mathrm{m}$ and $1 \mu \mathrm{m}$ magnification level, respectively which confirms that the nanoparticles formed are granular in form and spherical in shape having diameter $100-400 \mathrm{~nm}$.
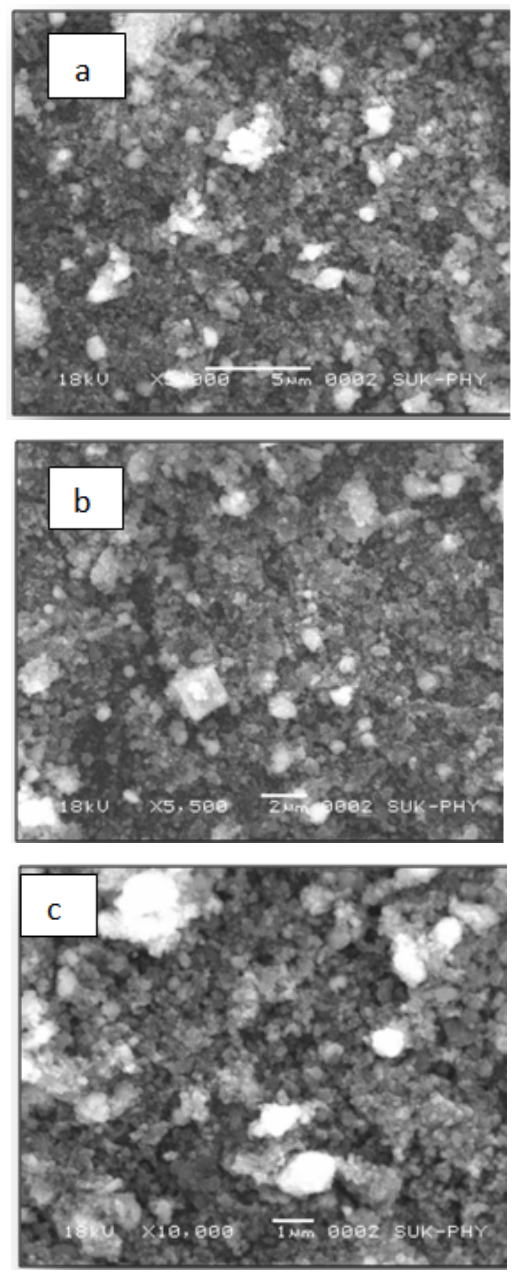

Fig. 9: (a, b, c) SEM images at high to low magnification levels

\section{Application}

\section{Antibacterial activity}

Antibacterial activity of nanoparticles was checked by using the disc diffusion method and Most Probable Number (MPN) test.

\section{Disc diffusion method}

By Disk diffusion method, antibacterial activity of synthesized nanoparticles against $E$. coli bacteria was checked.

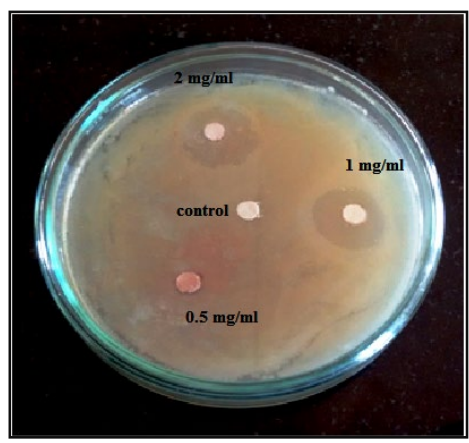

Fig. 10: Antibacterial activity of Magnetic NPs against $E$. coli bacteria by disc diffusion method

Figure.10 shows the antibacterial activity of synthesized nanoparticles against $E$. coli by disk diffusion method. At $2 \mathrm{mg} / \mathrm{ml}$ and $1 \mathrm{mg} / \mathrm{ml}$ concentration inhibition zones of $(15 \pm 0.15 \mathrm{~mm})$ was found while for $0.5 \mathrm{mg} / \mathrm{ml}$ concentration there was no inhibition. Therefore, it can be concluded that at higher concentration, synthesized nanoparticles show antibacterial activity.

\section{MPN}

The most probable number (MPN) test evaluates the potability of water. MPN analysis is a statistical method based on the random dispersion of microorganisms per volume in a given sample. In this method, a measured volume of water is added to a series of tube containing a liquid indicator growth medium. The media receiving one or more indicator bacteria like $E$. coli show growth and a characteristic colour change.

The samples were prepared as mentioned in the methodology for the MPN test. Sample A was simple water, sample B was quickly added and removed magnetic NPs and sample $\mathrm{C}$ contained the water treated with magnetic NPs for $24 \mathrm{~h}$. MPN tests were carried out for the same samples shown in fig. 11,12 and 13.
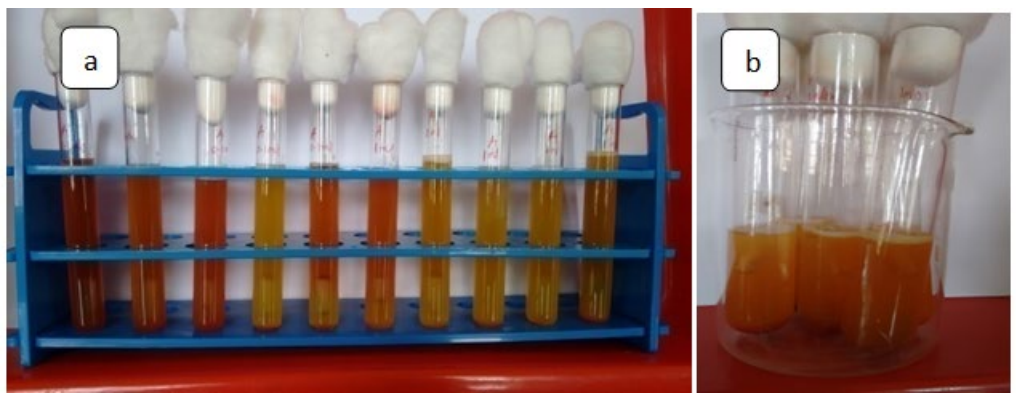

Fig. 11: (a) $0.1 \mathrm{ml}$ and $1 \mathrm{ml}$ of water sample $A$ (b) $10 \mathrm{ml}$ of water sample A 
Fig. 11 (a) (b) shows the MPN results for the sample A which was open well water. For this sample MPN test showed all positive tubes.
That means it has a high MPN index (table 3) which is tabulated in Maccrades table [12].

Table 3: MPN test results referred for sample A

\begin{tabular}{lll}
\hline Number of tubes giving positive reaction & MPN index \\
\hline 5 of $\mathbf{1 0} \mathbf{~ m l ~ e a c h ~}$ & $\mathbf{5}$ of $\mathbf{1 ~ m l ~ e a c h ~}$ & $\mathbf{5}$ of $0.1 \mathrm{ml}$ each \\
\hline 5 & 5 & 5 \\
\hline
\end{tabular}

In this MPN test (table 3), since all tubes became positive after incubation, that is colour change and gas formation occurred, indicating the presence of bacteria. So, we further tested for water sample B, which was quickly treated with magnetic nanoparticles. The results are shown below.

Fig. 12 (a) (b) shows the MPN results for sample B, which was quick treated water by magnetic nanoparticles for $10 \mathrm{~min}$. As we can see in the pictures, all tubes are positive that means colour change and gas formation occurred in all tubes.

In this MPN test, since all tubes became positive, the MPN index is 1600 (table 4), which is very high. It indicates the presence of bacteria. Therefore, after a quick treatment of water with magnetic nanoparticles, there was no change in its contamination. So further, we treated a water sample with magnetic nanoparticles for $24 \mathrm{~h}$. The results are shown below.

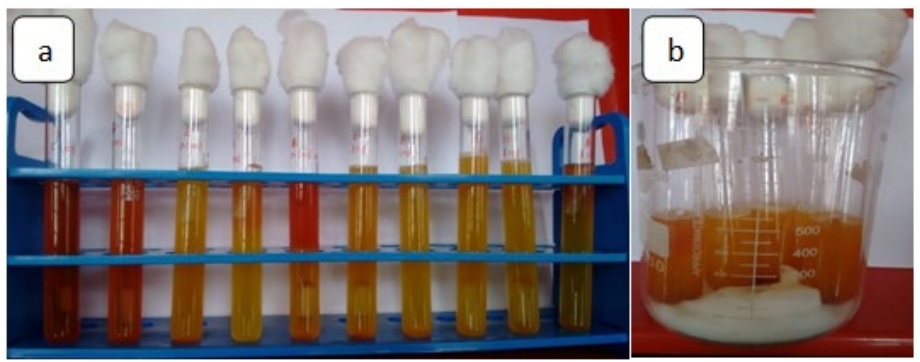

Fig. 12: (a) $0.1 \mathrm{ml}$ and $1 \mathrm{ml}$ of water sample $B(b) 10 \mathrm{ml}$ of water sample $B$

Table 4: MPN test results for sample $\mathrm{C}$

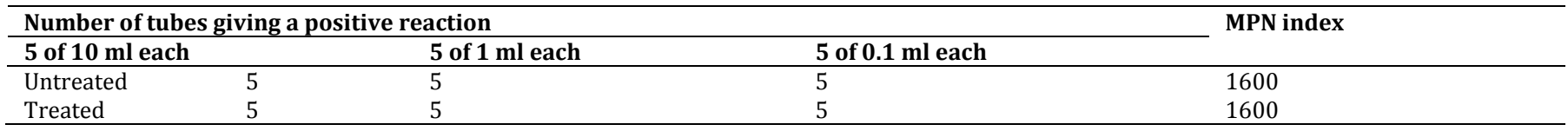

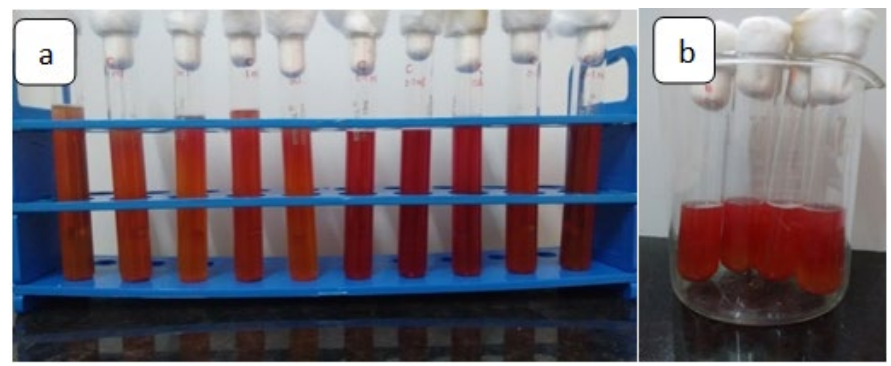

Fig. 13: (a) $1 \mathrm{ml}$ and $0.1 \mathrm{ml}$ of water sample $C$ (b) $10 \mathrm{ml}$ of water sample $C$

Fig. 13 (a) (b) shows the MPN results for sample $C$, which was treated with magnetic nanoparticles for $24 \mathrm{~h}$. In this test, 2 tubes of $0.1 \mathrm{ml}$ sample were seen to be negative, remaining all became positive. So there was a formation of bacteria in all tubes except 2 . Compared to Sample A and B the colour change in tubes not seen as intense in sample $\mathrm{C}$.

Table 5: MPN results for sample C

\begin{tabular}{llll}
\hline Number of tubes giving a positive reaction & & MPN index \\
\hline $\mathbf{5}$ of $\mathbf{1 0}$ ml each & & $\mathbf{5}$ of $\mathbf{1 ~} \mathbf{~ m l ~ e a c h ~}$ & $\mathbf{5}$ of $\mathbf{0 . 1} \mathbf{~ m l ~ e a c h ~}$ \\
\hline Untreated & 5 & 5 & 5 \\
Treated & 5 & 5 & 3 \\
\hline
\end{tabular}

In this MPN test (table 5) 2 tubes of $0.1 \mathrm{ml}$ didn't show positive results for colour and gas formation. The MPN index is 920 as per
Maccrades table [12], which shows that synthesized magnetic iron nanoparticles can reduce the bacterial count in water, although 
compared to sample B it show less colour and gas formation in tubes, but MPN index is not that much promising for quick result, so if we increase the time period of water treatment with Nanoparticles then MPN index will be more promising.

\section{CONCLUSION}

Magnetic nanoparticles of iron have been successfully synthesized by using a plant extract of Tridax procumbens. Synthesized powder of nanoparticles was observed visually before and after annealing with respective to its magnetic activity. Colour of synthesized nanoparticles before annealing was grey black and after annealing, it became brown. UV-VIS spectra showed peaks at $240 \mathrm{~nm}$ and 402 $\mathrm{nm}$, which indicated the formation of iron nanoparticles. XRD of synthesized nanoparticles was the crystallite size calculated by using Sherrer formula is $72 \mathrm{~nm}$. For the morphological characterization, SEM was taken, the SEM images show the spherical-shaped nanoparticles with a diameter 100 to $400 \mathrm{~nm}$.

Synthesised Magnetic NPs did show the Inhibition zone in disk diffusion method, the inhibition zones of about $(15 \pm 0.15 \mathrm{~mm})$. Further, we checked the applicability of synthesized magnetic iron nanoparticles for water treatment by testing MPN parameter for before and after its treatment on the water sample, which shown the decrease in the bacterial count. The MPN results showed that if we treat the water sample with synthesized nanoparticles for longer time results can be promising with the current result.

\section{FUNDING}

Nil

\section{AUTHORS CONTRIBUTIONS}

All the authors have contributed equally.

\section{CONFLICT OF INTERESTS}

Declared none

\section{REFERENCES}

1. Vikas Sharma, Akhilesh Sharma. Nanotechnology: an emerging future trend in wastewater treatment with its innovative products and processes. Int J Enhanced Research In Sci-Tech and Engineering; 2013. p. 1-8.

2. Weile Yan A, Andrew A Herzing, Christopher J Kiely, Wei Xian Zhang. Nanoscale zero-valent iron (nZVI): aspects of the coreshell structure and reactions with inorganic species in water. ] Contaminant Hydrology 2010;118:96-104.
3. Wan Zuhairi Wan Yaacob, Noraznida Kamaruzaman, Abdul Rahim Samsudin. Development of nano-zero valent iron for the remediation of contaminated water. Chemiical Engiineeriing Transactiions 2012:25-30. DOI:10.3303/CET1228005

4. Kuen Song Lin, Ni-Bin Chang, Tien Deng Chuang. Fine structure characterization of zero-valent iron nanoparticles for decontamination of nitrites and nitrates in wastewater and groundwater. Sci Technol Adv Mater 2008:025015. DOI:10.1088/1468-6996/9/2/025015

5. Sadia Saif, Arifa Tahir, Yongsheng Chen. Green synthesis of iron nanoparticles and their environmental applications and implications. Nanomaterials 2016:209. https://doi.org/10.3390/nano6110209

6. A P Tiwari, SJ Ghosh, SH Pawar. Biomedical applications based on magnetic nanoparticles: DNA interactions, Analytical Methods; 2015. p. 10109-20.

7. P Tiwari, SJ Ghosh, SH Pawar. Synthesis and characterization of functionalized superparamagnetic nanoparticles for isolation of DNA. Int J Pharma Bio Sci 2014;5:533-42.

8. C. Ikewuch Jude, C Ikewuchi Catherine, Ighoh Ngozi. Chemical profile of tridax procumbens linn. Pakistan Jl of nutrition 2009;8:548-50.

9. Sneha Shah, Sumita Dasgupta, Mousumi Chakraborty, Raji Vadakkekara, Murtaza Hajoori. Green synthesis of iron nanoparticles using plant extracts. Int J Biol Pharm Res 2014;6:549-52.

10. YY Patil, PD Raut. Studies on status of open wells in Kolhapur city. J Adv Sci Technol 2010;13:1-6.

11. Chitra Pai, Ujjwala Kulkarni, Manjusha Borde, Sowmya Murali, P Mrudula, Yashwant Deshmukh. Antibacterial activity of Tridax procumbens with special reference to nosocomial pathogens. Br J Pharm Res 2011;1:164-73.

12. APHA: Standard Methods for the examination of water and wastewater. 20th edition: Published by 1015 Fifteenth Street, NW; 1998.

13. Md Shariful Islama, Yoshihumi Kusumotoa, Md Abdulla-AlMamuna, Hirotaka Manakab, Yuji Horieb. Synthesis, characterization and application of dumbbell-shaped magnetic (Fe304 and-Fe203) nanoparticles against HeLa (Cancer) cells. Curr Nanosci 2012;8:811-8

14. Mahnaz Mahdavi, Farideh Namvar, Mansor Bin Ahmad, Rosfarizan Mohamad. Green biosynthesis and characterization of magnetic iron oxide (Fe304) nanoparticles using seaweed (Sargassummuticum) aqueous extract, molecules; 2013.

15. R Haul, $\mathrm{T}$ Schoon. Zur Struktur des ferromagnetischen Eisen(III)-Oxyds y-Fe203. Z Phys Chem 1939;44:216. 